\title{
A Direct Anatomical Study of the Morphology and Functionality of Disco-malleolar and Anterior Malleolar Ligaments
}

\author{
Estudio Anatómico Directo de la Morfología y Funcionalidad \\ de los Ligamentos Disco-maleolar y Maleolar Anterior
}

"Luis Miguel Ramírez Aristeguieta; * Luis Ernesto Ballesteros Acuña \& ${ }^{* * *}$ German Pablo Sandoval Ortiz

\begin{abstract}
RAMÍREZ, L. M.; BALLESTEROS, A. L. E. \& SANDOVAL, O. G. P. A direct anatomical study of the morphology and functionality of disco-malleolar and anterior malleolar ligaments. Int. J. Morphol., 27(2):367-379, 2009.

SUMMARY: The disco-malleolar and anterior malleolar ligaments are common to the middle ear, the temporomandibular joint and the jaw, all of them sharing a common embryological origin; these ligaments' morphometric and functional aspects were studied in 23 temporal bones. Experimental design: The epitympanum roof and the temporomandibular joint roof were elevated by micro-dissection of the middle cranial fossa, exposing both disco-malleolar and anterior malleolar ligaments and their association with the malleus, the temporomandibular joint disc and the mandibular lingula. Principal observations: Both ligaments start in the malleus and take anterior and divergent routes towards the temporomandibular joint and lingula, passing through Huguier's canal. The disco-malleolar and anterior malleolar ligaments' mean lengths were $6.88 \mathrm{~mm}$ (SD 0.81) and 4.22mm (SD 1.17), respectively, no statistically significant difference being revealed between the sides. Temporomandibular joint disc traction was applied for verifying malleus mobility; malleus movement was observed when applying disco-malleolar traction in 30.5\% of the samples. Correlation was observed between malleus movement and disco-malleolar length $(\mathrm{R} 2=-0.499, \mathrm{p}<0.05)$. Both ligaments common to the stomatognathic system and middle ear were present in all specimens. Conclusions: There was an anatomical and functional relationship between human TMJ and the middle ear.
\end{abstract}

KEY WORDS: Oscicular chain; Temporomadibular joint; Otic symptoms; Disco-malleolar ligament; Anterior malleolar ligament.

\section{INTRODUCTION}

The middle ear and the stomatognathic system are closely related. Myrhaug (1964) stated that the ossicular chain and middle ear muscles ontogenically belonged to the masticatory system and serve the hearing system. Interestingly, in other ancestral species (reptile fossils), the jaw was fixed with the oscicles, which constrain acoustic signals (Allin, 1975). This scenario is not currently applicable to humans; however, the close relationship of the temporomandibular joint (TMJ) and the middle ear make them neighbours (embryological, anatomically and physiologically speaking), although performing different tasks (Fig. 1).

TMJ and middle ear development is complex in humans and still debatable (Proctor, 1967). The first branchial arc (Meckel's cartilage) forms the jaws from its ventral part and the ossicular chain from its dorsal part, partially joining the second branchial arch (Reichert's cartilage) (Strickland et al., 1962). Vascular, nervous and ligamental connections between the TMJ and middle ear growth persist; they survive due to common Meckel's structure continuity through the petro-tympanic fissure, which never completely closes, thereby forming Huguier's canal (Rodriguez Vazquez et al., 1991, 1993). The malleus is closely related to condylar and temporal blastemas with fibrous connections through this petro-tympanic fissure, which Rees (1954) named the disco-malleolar ligament (DML). This is the same structure to which Bossy and Gaillard attributed vestigial characteristics from the first branchial arc (Rees; Bossy \& Gaillard, 1963; Youdelis, 1966; Misurya, 1976; Perry \& Xu, 1985; Thilander \& Carlsson, 1976; Sadler, 1998; Yoshikuni, 1993; Wong, 1985).

\footnotetext{
* Associate Professor, DDS, MS, M. Sc. Basic Science Department, Universidad Industrial de Santander, Post Grade Research Department, Universidad Santo Tomas de Aquino. Bucaramanga, Colombia.

** Associate Professor, Basic Science Department, Universidad Industrial de Santander, Bucaramanga, Colombia.

*** Assistant Professor, Surgery Department, Universidad Industrial de Santander, Bucaramanga, Colombia.
} 

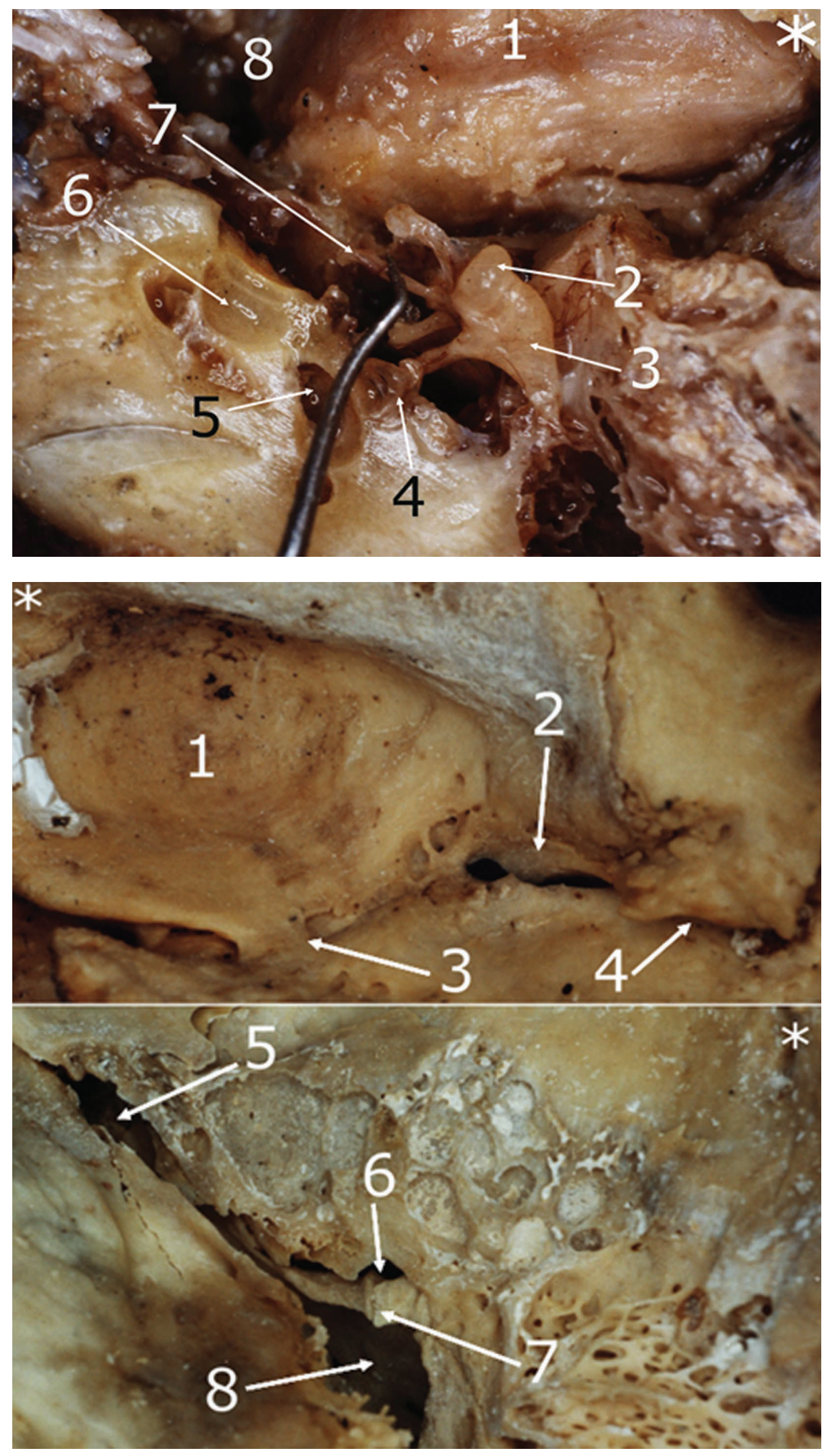
The iter chorda anterious (or Huguier's canal) is the structure connecting the TMJ and the middle ear; this is where the chorda tympani nerve exits from the middle ear (Fig. 2) (Tóth et al., 2006). Sato et al. (2008) have used radiology (cone beam CT) for finding different dimensions and forms for this TMJ and middle ear or Huguier's canal (Sato et al.). Marasa \& Ham (1988) have suggested that TMJ inflammatory or functional disorders can spread throughout Huguier's canal to the middle ear and produce otitis media due to this foramen's dimensions (Scolozzi et al., 2004; Regev et al., 2003; Takes et al., 2000).

Pinto's and Komori's dissections in humans (Pinto, 1962; Ash \& Pinto, 1991; Komori et al., 1986) and other dissections of adults and foetuses (Rodriguez Vazquez et al., 1993, 1998; Loughner \& Larkin, 1989; Morgan et al., 1995; Ioannides, 1983; Mérida Velasco et al., 1997; Coleman, 1970; Alkofide et al., 1997; Rodriguez Vazquez et al., 1992; Gola et al., 1997) have established an anatomical link between the TMJ, the middle ear and the lingula from both sides of Huguier's canal. The DML and anterior malleolar ligament (AML) pass through this canal and connect the malleus' anterior process (Gracilis process) with the TMJ disc and lingula (Hoshino, 1988; Toledo Filho et al., 1985). The DML is an embryological remnant of the external pterygoid muscle; it is located more laterally to the AML and inserts into the postero-supero-medial TMJ capsule and retrodiscal portion of the TMJ disc (Pinto). The AML is placed more medially and joins the maleolo-mandibular or sphenomandibular ligament (EML), being accompanied by the chorda tympani nerve. Hence, the AML was considered to be a continuation of the EML by Burch (1970) because its origin is in the anterior process of the malleus and united sphenoid spine and petro-tympanic components of the EML to ultimately become inserted into the lingula or the jaw body's spix spine (Fig. 3) ( Garg \& Townsend, 2001). The EML is an embryological remnant of Meckel's cartilage and changes its dimensions throughout its entire trajectory from lingula to cranial base to unite the AML on entering the middle ear in Huguier's canal (Loughner \& Larkin). Both the DML and AML are fixed in the malleus' ventral area (anterior process). They exit anteriorly from the malleus' anterior process towards the tympanic wall in the petrotympanic fissure (Huguier's canal), expanding it medio-laterally like a horizontal "V" (Ogutcen-Toller, 1995; Ogutcen-Toller \& Keskin, 2000). The chorda tympani nerve emerges with the AML (Pinto; Komori et al.), both ligaments being separated by an osseous triangular crest in Huguier's canal (Fig. 2).

The possible biomechanical connections between these ligaments are very controversial, especially due to their involvement in any otic-referred symptoms, which may be produced. Both ligaments are described in this study using dissections of human temporal specimens, the TMJ and middle ear being accessed through the middle cranial fossa. Malleus mobility was registered during masticatory structure traction: anterior jaw (TMJ disc traction) for the DML and jaw overclosure and lateral jaw movements for the AML and EML, respectively.

\section{MATERIAL AND METHOD}

Twenty-three fresh temporal blocks ( $7 \mathrm{~cm}$ side) were extracted from 11 male and 1 female non-reclaimed, lesionfree cadavers; these samples were donated by the Instituto de Medicina Legal in Bucaramanga, Colombia, and research on such human samples was approved by the Universidad Industrial de Santander's Ethics' Committee. Twenty-two samples were paired and one (left-hand side) was left unpaired; the samples were frozen and then immersed in 1:10.000 thimerozal in $0.9 \%$ saline solution for one week (to keep the tissue soft) until used for dissection purposes. Formaldehyde was not used to avoid it inappropriately fixing the tissues for our study purposes.

The access route for the micro-dissection consisted of a superior approach through the middle cranial fossa. Both epitympanun and TMJ roofs were removed, revealing both disco-malleolar and anterior malleolar ligaments and their attachment to the malleus and the TMJ disc. An electronic calliper (Mitutoyo) was used for recording all measurements in centesimal $\mathrm{mm}$. The tympanic wall septum was used as a reference area for measurements and morphometric description. Pre-septal and supra-septal DML and AML lengths were measured (a 15x optical zoom being used for all measurements).

A colour dotted mark was visually recognised on the malleus head when recording malleus mobility by TMJ-jaw traction. Stereotypical anterior and superior jaw forces were then tested: anterior TMJ disc traction (protrusion) for the DML and jaw over-closure and lateral movements for the AML and EML. These movements tried to reproduce some physiological (protrusion and lateralisation) and pathological (overclosure) scenarios. All specimens were mechanically fixed with screws before traction and tightly immobilised in a table-vice. The movements were done manually by holding the jaw before starting; such protrusion, overclosure and lateralisation range of movement was towards the extreme limit determined by a sample's anatomical parameters. These movements started with the extreme posterior and superior mandible fossa condyle position. The protrusion movement finalised when the condyle-disc complex reached 


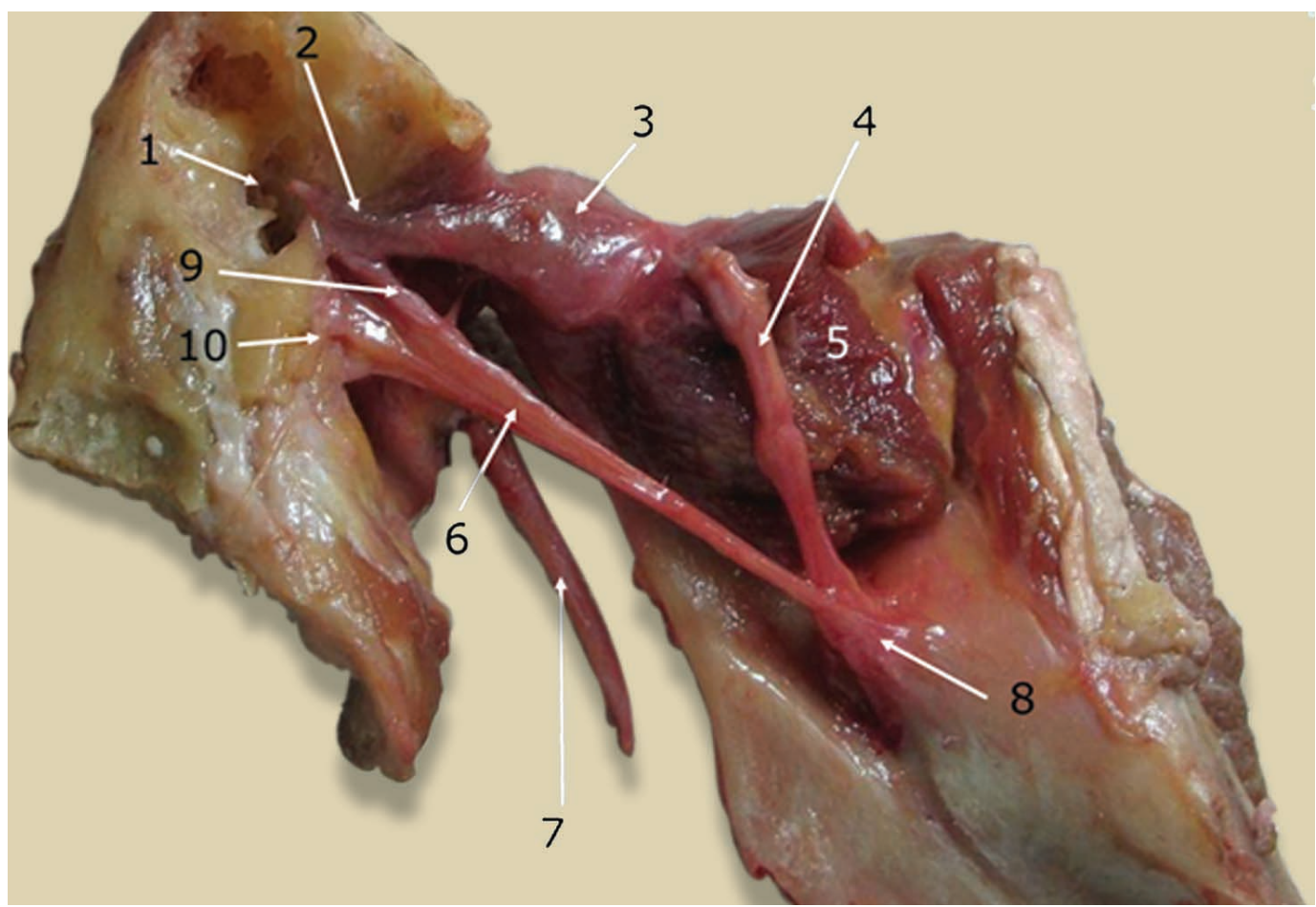

Fig. 3. Left TMJ, mandible ramus and middle ear medial view. 1. Tympanic cavity, 2. DML bilaminar area union, 3. TMJ disc, 4. alveolar nerve sectioned and retracted over external pterygoid muscle, 5. external pterygoid muscle, 6. EML, 7. styloid process, 8. lingula, 9. AML fixing to EML lateral surface, 10. sphenoid spine.

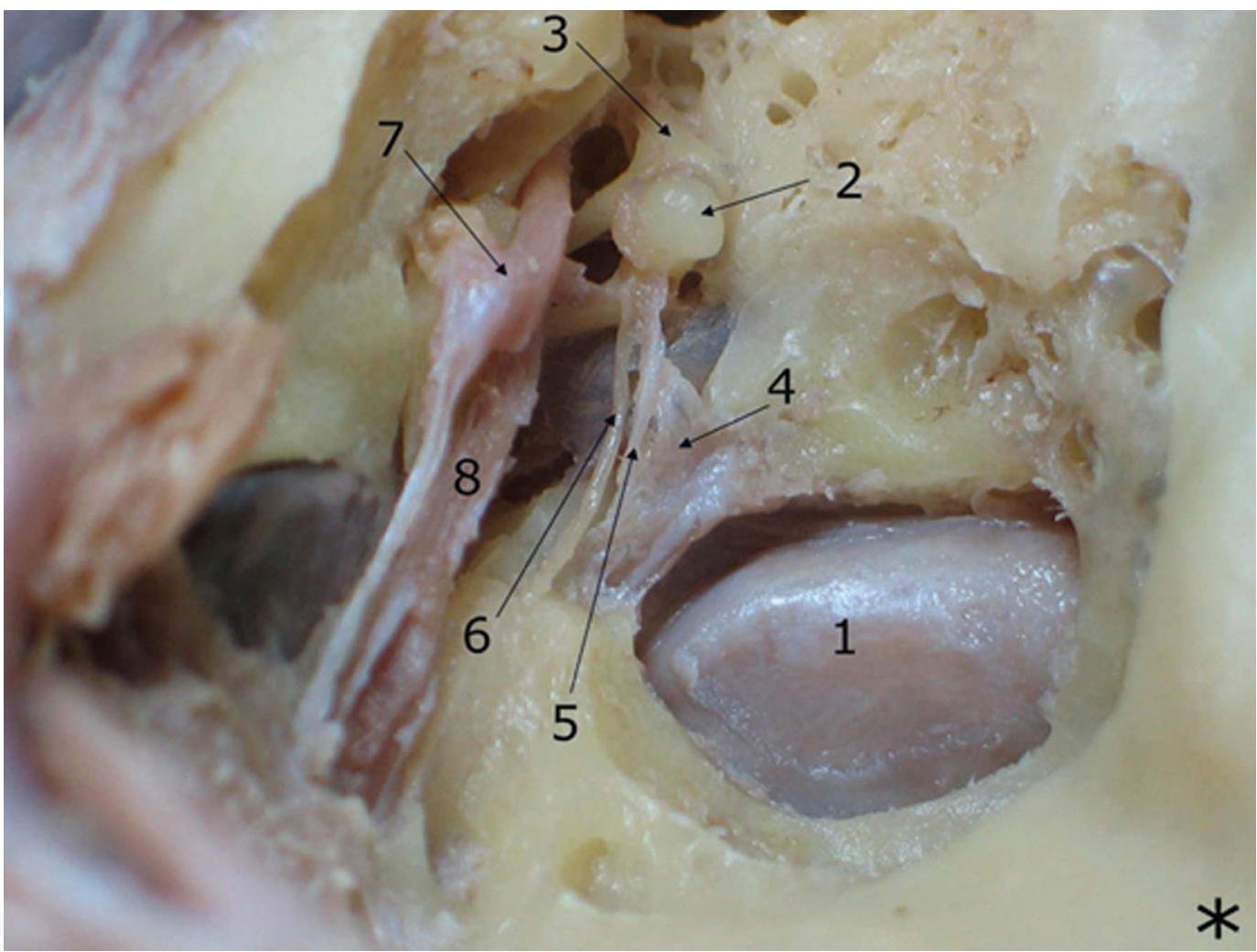

Fig. 4. Superior and antero-medial view of left middle ear and TMJ. * Antero-lateral sample orientation. 1. TMJ disc, 2. malleus head, 3. incus, 4. DML, 5. AML, 6. chorda tympani nerve, 7. VII cranial pair geniculated ganglion, 8. tensor tympani muscle. 
or surpassed the temporal eminence crest in extreme traction. The overclosure movement finalised when the condyle-disc complex reached an extreme orbit in the mandibular fossa; the same initial position was considered for extreme lateral movements. All findings were recorded with digital images and all measurement data was recorded on a collection format. Parametric and non-parametric tests were done.

\section{RESULTS}

The DML and AML (fixed to EML) were observed in all samples. DML and AML morphology assumes a triangular form in the petrotympanic fissure with a posterior vertice in the anterior process of the malleus, an anterior base combining with the bilaminar TMJ disc and TMJ capsule area (posterior-supero-medial area), one medial side formed by the AML and chorda tympani nerve emerging from the middle ear and a diffuse lateral side, which we could not relate to any other structure (Fig. 4). The AML was joined to the most lateral aspect of the EML in the sphenoid spine, descending towards the lingula (Fig. 3). The entire complex (DML and AML) was located in Huguier's canal (petrotympanic fissure). Both ligaments were separated by an osseous crest on the horizontal floor of Huguier's canal (Fig. 5). The DML took a lateral course and the AML a medial one with the chorda tympani nerve as it passed through Huguier's canal to the sphenoidal spine.

Both ligaments' mean lengths were recorded (Table I): the DML was $6.88 \mathrm{~mm}$ (SD 0.81) and AML $4.22 \mathrm{~mm}$ (SD 1.17). The tympanic wall septum separating the TMJ and the middle ear was used as a reference area for measuring both ligaments' pre-septal and supra-septal lengths (Fig. 6); DML pre-septal length was $1.45 \mathrm{~mm}$ (SD 0.19 ) and supra-septal length $5.42 \mathrm{~mm}$ (SD 0.61), having no significant difference between sides ( $\mathrm{t}$ paired test $=0.809$, $\mathrm{p}=0.44)$. AML measurements revealed a shared medial trajectory with the chorda tympani nerve before they became hidden in the petro-tympanic fissure sulcus towards the sphenoid spine. AML pre-septal mean length was 1.45

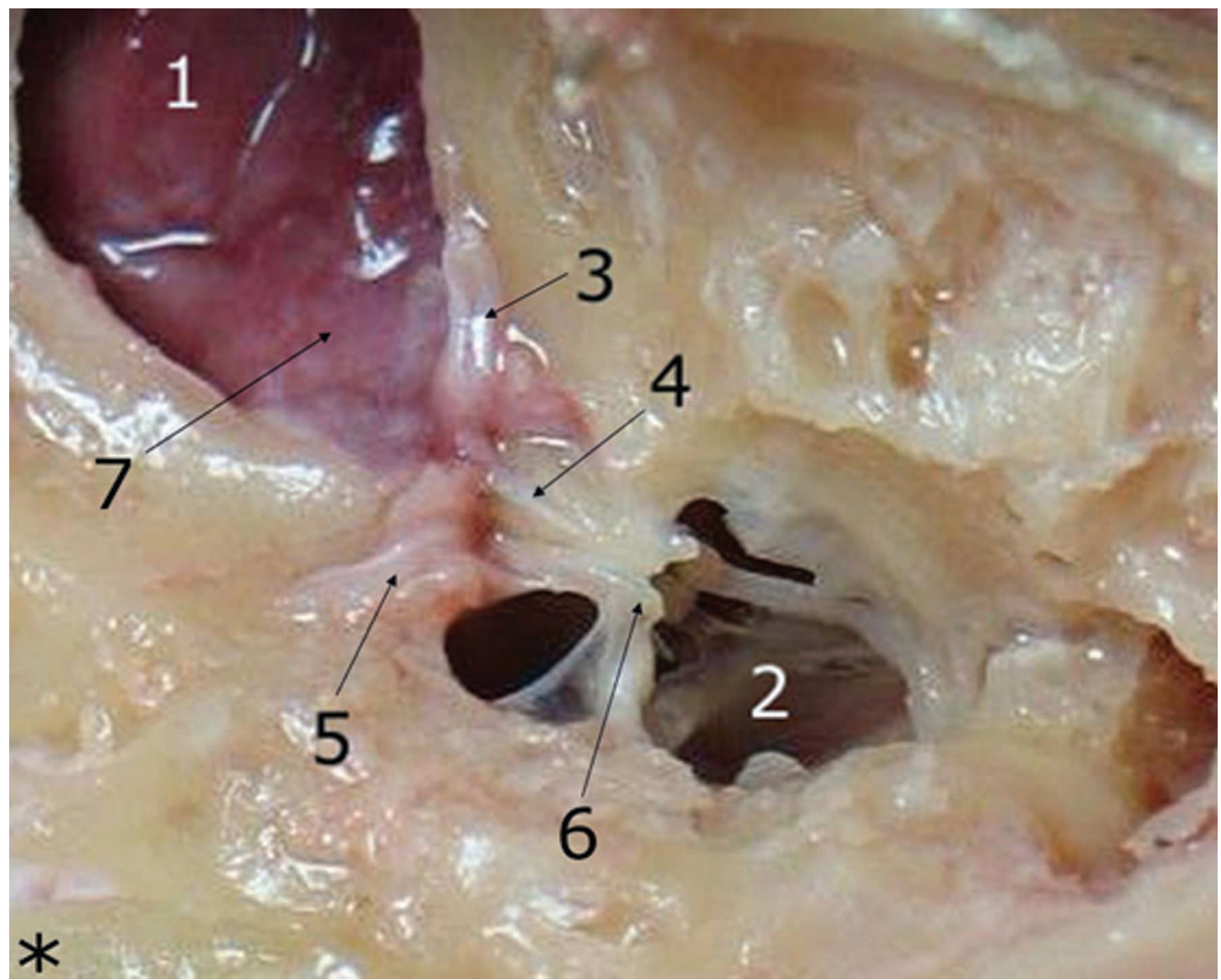

Fig. 5. Superior and postero-medial view of right middle ear and TMJ. * Postero-medial sample orientation. 1. TMJ disc, 2. middle ear, 3. DML antero-laterally separated from the lateral side of Huguier's canal, 4. DML and AML Huguier's canal septum, 5. AML antero-medially separated from the medial side of Huguier's canal, 6. chorda tympani nerve supraseptal trajectory, 7. TMJ bilaminar zone. 


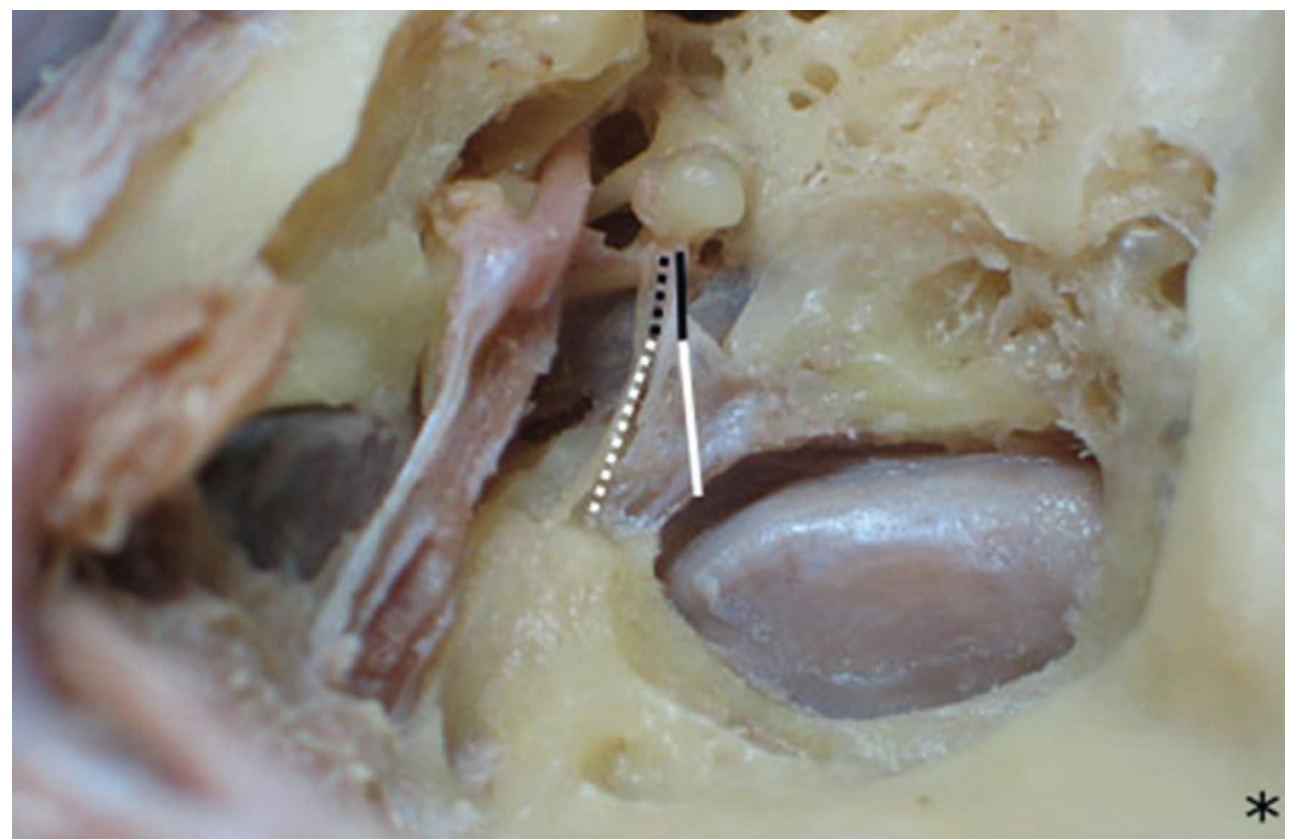

Fig. 6. Superior and antero-medial view of left middle ear and TMJ. * Antero-lateral sample orientation. Continuous black line: DML pre-septal portion, continuous white line: DML supra-septal portion, segmented black line: AML pre-septal portion, segmented white line: AML supra-septal portion.

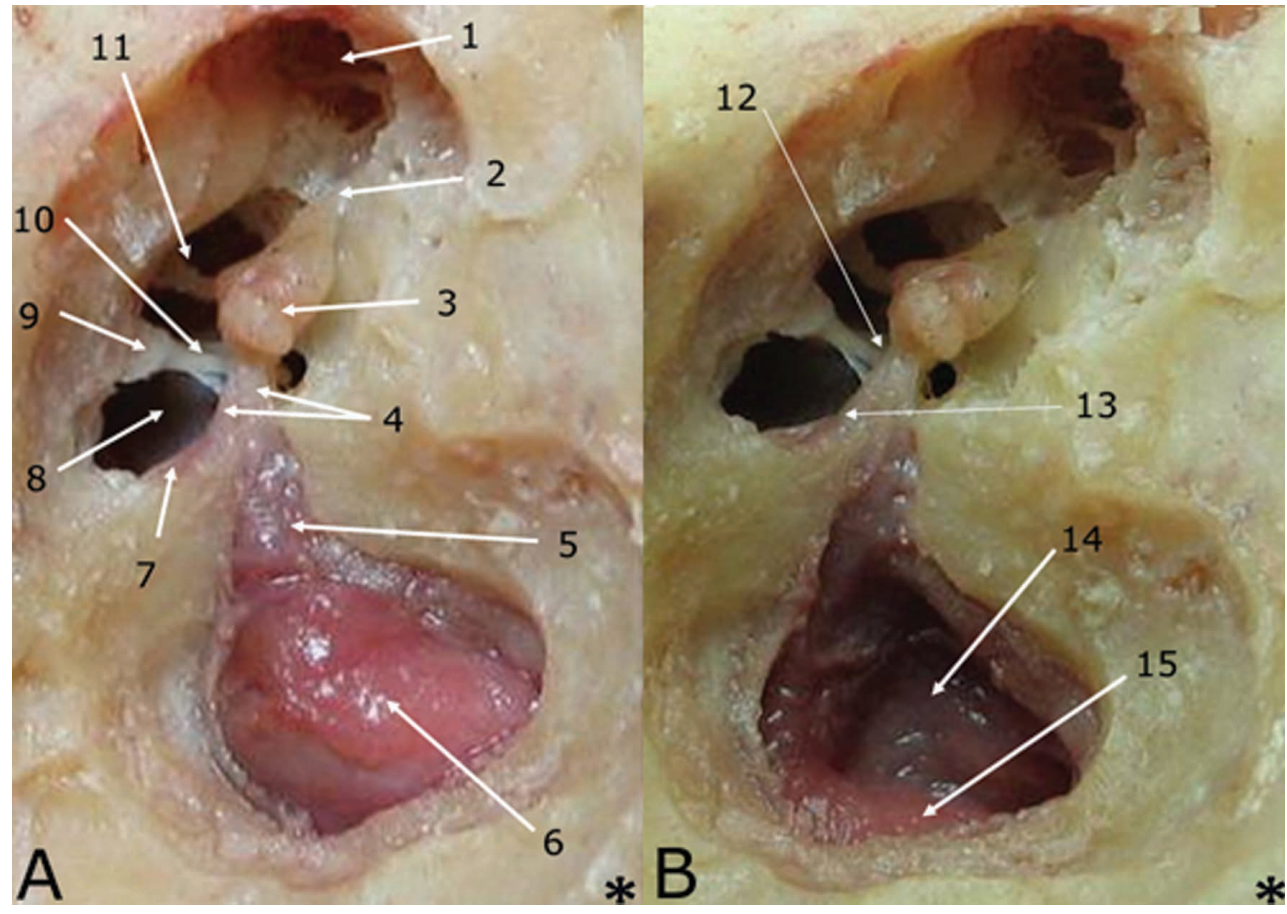

Fig. 7. TMJ disc anterior traction (protrusion) for the DML. Superior and antero-medial view of left middle ear and the TMJ. * Antero-lateral sample orientation. Fig. A, 1. mastoid aditus, 2. incudal fossa, 3. incudo-malleolar joint, 4. the DML (short arrow) and AML (long arrow) emerging from the malleus anterior process, 5. DML fixing TMJ bilaminar zone, 6. TMJ disc, 7. AML in its supra-septal medial course, 8 . the internal face of tympanic membrane, 9. chocleariform process, 10 . tensor tympani muscle tendon, 11. incudo-stapedial joint, 12. chorda tympani nerve over tensor tympani muscle tendon, 13. chorda tympani nerve and AML medial course, 14. TMJ bilaminar zone stretched in excursive tractional TMJ movements, 15. TMJ disc in extreme protrusive movement.
$\mathrm{mm}(\mathrm{SD} 0.19)$ and 2.77 $\mathrm{mm}$ (SD 0.98) for its supra-septal portion, no significant difference being noted for the sides (t paired test: 0.492 , $\mathrm{p}=0.63$ ).

Malleus head anterior mobility was observed (by TMJ disc protrusion, Fig. 7) in $30.5 \%$ of the samples for the DML (approximately $1 \mathrm{~mm}$ range); such movement was posteroanterior but we could not determine a possible rotational effect for the bone or any tympanic membrane traction deformation. No movement was observed in any of the samples when AMLrelated traction movements (overclosure and lateral) were made. Correlation was observed between malleus movement and DML length (R2=-0.499, $\mathrm{p}<0.05)$.

\section{DISCUSSION}

A century ago the origin of some otic symptoms (collectively known as temporomandibular disorders) was attributed to stomatognathic system dysfunction. Monson \& Wright related jaw position with hypoacusis in the infant and adult population in 1920 . Goodfriend correlated otic symptoms with the TMJ in 1933 (Parker \& Chole, 1995). Costen (1934) associated such otic symptomatology with 
Table I. Results of ligament traction (jaw body closing and protruding) and length measurements in mm for the DML and AML.

\begin{tabular}{ccccccccccc}
\hline Sample & Sex & Side & Closing & Protuding & $\begin{array}{c}\text { AML Pre- } \\
\text { Sept }\end{array}$ & $\begin{array}{c}\text { AML Supra- } \\
\text { Sept }\end{array}$ & $\begin{array}{c}\text { AML } \\
\text { Total }\end{array}$ & $\begin{array}{c}\text { DML Pre- } \\
\text { Sept }\end{array}$ & $\begin{array}{c}\text { DML Supra- } \\
\text { Sept }\end{array}$ & $\begin{array}{c}\text { DML } \\
\text { Total }\end{array}$ \\
\hline 0 & M & L & N & Y & 1.46 & 2.38 & 3.84 & 1.46 & 5.74 & 7.20 \\
1 & M & L & N & N & 1.45 & 2.77 & 4.22 & 1.45 & 5.72 & 6.87 \\
2 & M & R & N & N & 1.62 & 0.96 & 2.58 & 1.62 & 5.14 & 6.76 \\
3 & M & L & N & N & 1.38 & 2.14 & 3.52 & 1.38 & 4.84 & 6.22 \\
4 & M & R & N & N & 1.58 & 4.84 & 6.42 & 1.58 & 4.52 & 6.10 \\
5 & F & R & N & N & 1.44 & 1.10 & 2.54 & 1.44 & 5.12 & 6.56 \\
6 & F & L & N & N & 1.48 & 1.18 & 2.66 & 1.48 & 5.02 & 6.50 \\
7 & M & R & N & N & 1.60 & 2.12 & 3.72 & 1.60 & 6.36 & 7.96 \\
8 & M & L & N & N & 1.60 & 2.12 & 3.72 & 1.60 & 5.10 & 6.70 \\
9 & M & L & N & Y & 1.54 & 3.22 & 4.76 & 1.54 & 5.34 & 6.88 \\
10 & M & R & N & Y & 1.50 & 3.60 & 5.10 & 1.50 & 5.86 & 7.36 \\
11 & M & L & N & Y & 1.10 & 2.90 & 4.00 & 1.10 & 6.04 & 7.14 \\
12 & M & R & N & N & 1.08 & 3.40 & 4.48 & 1.08 & 5.54 & 6.62 \\
13 & M & R & N & N & 1.60 & 2.18 & 3.78 & 1.60 & 6.16 & 7.76 \\
14 & M & L & N & N & 1.68 & 2.02 & 3.79 & 1.68 & 5.10 & 6.78 \\
15 & M & L & N & Y & 1.56 & 3.22 & 4.78 & 1.56 & 5.34 & 6.90 \\
16 & M & R & N & Y & 1.40 & 3.80 & 5.20 & 1.40 & 5.98 & 7.38 \\
17 & M & L & N & Y & 1.12 & 3.28 & 4.40 & 1.12 & 7.04 & 8.16 \\
18 & M & R & N & N & 1.12 & 3.40 & 4.52 & 1.12 & 5.54 & 6.66 \\
19 & M & R & N & N & 1.42 & 1.16 & 2.58 & 1.42 & 5.34 & 6.76 \\
20 & M & L & N & N & 1.34 & 2.22 & 3.56 & 1.34 & 4.84 & 6.18 \\
21 & M & L & N & N & 1.58 & 4.84 & 6.42 & 1.58 & 4.52 & 6.10 \\
22 & M & R & N & N & 1.78 & 4.76 & 6.54 & 1.78 & 4.82 & 6.60 \\
\hline Mean & & & & & 1.45 & 2.77 & 4.22 & 1.45 & 5.42 & 6.88 \\
SD & & & & & 0.19 & 0.98 & 1.17 & 0.19 & 0.61 & 0.81 \\
\hline
\end{tabular}

TMJ disorders, in 1934 (Costen's syndrome) (Shapiro \& Truex, 1943). Kuttila \& Kuttila have found that an evident pathology in the hearing system can be diagnosed in less than $50 \%$ of patients suffering from otalgia (Kuttila \& Kuttila, 1999, 2001). It appears that functional and inflammatory TMJ and craniofacial muscular disorders are associated with secondary otological-referred symptoms (Gelb \& Tarte, 1975; Ramirez et al., 2008).

The range of tympanic membrane deformation in conducting sound energy must be understood when trying to ascertain the possibility of motion from the DML and AML on malleus ossciles. Tonndorf \& Khanna (1972) used time-average holography to show that an intense acoustic stimulus (111-121 dB) can deform the tympanic membrane by no more than nanometers or possibly a micrometer, depending on the frequency and place for tympanic membrane measurement (Sun et al., 2002). Tympanic membrane and middle ear vibration produced by sound energy is thus on the nanometer scale. The auditory threshold thus responds to sub-angstrom ossicular motion (Békésy, 1960; Dalhoff et al., 2007), this finding has been widely corroborated by Wada et al. (1992, 2002; Koike et al., 2002) using better-quality tympanometry equipment with low probe tone frequency (time-average speckle pattern interferometry) and finite element analysis at different frequencies and pressures in human and other species' hearing systems.

According to Eckerdal (1991), the DML and AML range of movement depends on their fibrous connections to Huguier's canal, thereby corroborating Coleman's findings (Coleman). Our findings concerning 30.5\% DML traction malleolar mobility correlated well with Sato et al. who showed a spacious Huguier's canal in $29.2 \%$ of samples, suggesting a wide foramen which could allow 
free passage of its inner structures. The samples' DML traction malleolar mobility was recorded with a $15 \mathrm{x}$ optical zoom which surely allows seeing movement ranging from $800-1000 \mu \mathrm{m}$ or higher, thereby making it just possible to observe a greater range of movement produced by TMJ disc traction but not those produced by middle ear physiological nanometer dynamics. If the ossicular chain can thus transmit a nonometric tympanic vibration through two joints from tympanic membrane to inner ear then, with more than four ligaments and two muscles having an effective area and lever relationship, it would thus be very possible to have a potential DML and AML effect on ossicular chain spatial disposition when TMJ-jaw traction is applied to them by the malleus.

Experiments have demonstrated that AML fixation (stiffness) is dominant at low frequencies. Although low frequency tinnitus has been reported to be very rare, it may vary in pitch from low frequency to high frequency, intermittent or permanent and vary in intensity; it cannot be ruled out that it is caused by ossicular fixation and/or a low admittance pattern. The work of Nakajima et al. (2005) has ruled out the idea that ligamental motion may not produce an auditory effect by appreciable excitation of the inner ear due to high-pass filtering by different systems (helicotrema, incudo-malleolar, incudo-stapedial and oval anullar ligament joints). They revealed reduced auditory sensitivity (8-10 dB loss) when the AML was partially fixed and a larger loss (15-35 dB) when it was totally fixed. This proved that restraining the osscicles produced an increase in the ear's impedance. They tried to simulate an otosclerosis lesion because AML fixation clinically occurs in combination with this pathology (Zhao et al., 2002). This experimental model also took into account this ligament structure's adjustment power in sound transmission (Huber et al., 2003). In this sense, whether such motion at low frequencies involved in TMJ-jaw motion can produce enough sound to be heard at an auditory threshold close to $1 \mathrm{~Hz}$ (the stapes move at least one micron) is not unsure.

Huguier's canal's morphological dimensions play a paramount role in the above possibility. Huguier's canal has a slender funnel-like form in the petrotympanic fissure (being wider near the TMJ and narrower near the middle ear). Sato et al. and Eckerdal measured such dimensions at three saggital places (near the TMJ, the middle area and near the middle ear); these were 4.1, 1.9 and $0.9 \mathrm{~mm}$, respectively, according to Sato et al., and 2.75, 1.9 and $1.05 \mathrm{~mm}$, respectively, according to Eckerdal. Estimations of Huguier's canal length have been seen to differ, being quite ample for Eckerdal (1.9 to $11.5 \mathrm{~mm}$ ) when compared to our measurements $(6.88 \mathrm{~mm}, \mathrm{SD} 0.81)$ and those of
Komori et al., (2.5 mm, SD 1.8). Regarding ligament width, Loughner \& Larkin recorded $0.2 \mathrm{~mm}$ (SD 0.2) for the DML and $0.8 \mathrm{~mm}$ (SD 0.2) for the AML in 52 samples. Alkofide et al. recorded $0.14 \mathrm{~mm}$ (SD 0.04) for the AML in 37 samples whilst Cheng \& Gan (2008) found $0.81 \mathrm{~mm}$ (SD 0.22) for the AML in 9 samples. We did not measure AML and DML width, but corroborated other findings in our dissections with thin and (on some occasions) fragile attributes for these structures. Such heterogeneous Huguier's canal morphology suggests a diverse permissive movement ability for the DML and AML when a force is applied to them and transmitted via ossicular chain vibration dynamics.

To a certain extent we have the same opinion as Eckerdal regarding the idea that Huguier's canal adherence can restrict the ligaments observed in our dissections. On the other hand, we do not consider such adherence able to impede (in the rest of the $30.5 \%$ of our samples) nanometer movement transmission from TMJ anterior traction force during protrusion. Differing explanations have arisen from these ligaments' morphology regarding Huguier's canal and this canal's dimensions, strengthened by ossicular chain dynamics' physiology. Cheng \& Gan found that the AML's mean pre-septal length was $1.83 \mathrm{~mm}$ (SD 0.32), this being close to ours $(1.45 \mathrm{~mm}, \mathrm{SD} 0.19)$; good viscoelastic performance was calculated for tension resistance (1.05 $\mathrm{MPa})$ and stretching resistance (1.51 $\mathrm{MPa}$ ), thereby assuring force transmission from the TMJ to the middle ear malleus. Disorganised surface collagen disposition was found regarding this structure's morphology (regarding Huguier's canal walls), enveloping a wide and well-organised longitudinal collagen band as a double collagen layer assembly. This characteristic, plus its width, mechanical resistance and sound energy transmission magnitude, makes Eckerdal's adherence model for Huguier's canal doubtful (Eckerdal). Correlation was also obtained between malleus movement and DML length, thereby adding an extra variable to be taken into account (especially for Huguier's canal mixed morphology and proximity), making these ligaments dynamic structures.

Interestingly, ipsilateral referred otic symptoms have been found in TMJ pathologies, as demonstrated by Ren et al. (1995) and Kuttila et al. (2005), who found a positive correlation between tinnitus and ipsilateral TMJ disorder. In 1933, Bernstein et al. (1969) observed that tinnitus intensity and quality could be modified in extreme jaw movements. This picture of mobility was taken from a surgical scenario when Loughner \& Larkin reported that damage to the ossicular chain had been caused by TMJ condylar distraction surgery (Jones \& Horn, 1989; 
Steigerwald et al., 1996; Tsuyama et al., 2000). Baldursson \& Blackmer (1987) reported a correlation between temporomandibular dysfunction and sensorineural hearing loss in a controlled study using 50 patients; a notch loss of audiometric configuration was found at $1-2 \mathrm{KHz}$ (250$4.000 \mathrm{~Hz}$ range).

A TMJ disorder may stretch the DML and AML, thereby affecting middle ear structure equilibrium (Eckerdal; Cheynet et al., 2003; Kim et al., 2004; Wright $\&$ Bifano, 1997). The spread of forces through cranial bone sutures was treated by Libin in 1987 (Libin, 1987) and suggested that ligaments common to neighbouring structures could become tensioned during normal physiological mobilisation and in abnormal temporal bone trauma. Retrodiscal tissue elasticity can normally act as an energy buffer in spreading movement from the TMJ to the middle ear by such common ligaments; however, TMJ disc luxation or oedematous pressure from an inflammatory disorder could certainly cause tension on the malleus through Huguier's canal (Johansson et al., 1990; Myers, 1988; Williamson, 1990; Luder, 1993; Schaefer, 2001).

It thus seems that otic symptoms (tinnitus, otalgia, dizziness and hypoacusis) corresponding to altered ossicular spatial relationships (such as conductive middle ear pathologies) can also be produced from masticatory system pathologies. Otalgia produced in tympanic membrane tension and tinnitus, dizziness or hypoacusis by the inner ear being stimulated by such mechanical transmission is viable in such a ligamental model (Dai et al., 2007).

Indeed, recalling that the ossicular chain rotational axis was assumed to be a straight line from the malleus' anterior process (where the AML and DML become attached to it) to the incus' short process, then an anteroposterior axis may be obtained having proven complex movement patterns when sound frequencies are increased (Wada et al.; Huber et al.). If potential roles for both the AML and DML are considered in fixing low frequency sound ranges (such as tensor tympani and stapedial muscle activity execution during sound protection and discrimination mechanisms) (Chan \& Reade, 1994), then this produces another possible ossicular fixation mechanism in sound transmission when the mandible is protruded which would be interesting to study as a natural acoustic accommodation reflex.

Concerning EML, we agree with the findings of Abe et al. (1997), who found that this ligament was fixed inferiorly to the jaw (lingula) and superiorly to the sphenoid spine (medial side) and the AML (lateral side); however, we could not account for an additional attachment to the TMJ disc in our dissections. Alkofie et al. studied AML and EML structural characteristics in 37 specimens, determining that the EML reached the malleus $(8.1 \%)$ and the middle ear $(67.6 \%)$, whilst the AML passed through the petrotympanic fissure with the EML (58.3\%), suggesting guaranteed connectivity between both ligaments. Regarding EML mechanics, Burch (1966) found that it relaxed during maximum jaw opening and tensed during overclosure; however, it has been suggested that it can be stretched during lateral jaw movements (Ouchi et al., 1998). Both AML and EML ligaments can thus be tensioned in several situations, which may alter the ossicular chain (Burch, 1970), although this could not be observed in our experiment. Malleus head mobility by DML was positively observed in $30.5 \%$ of the samples; however, minor nanometer transmission cannot be ignored for all ligaments (DML, AML, EML) regarding ossicular chain movement magnitude.

Secondary referred pathologies must be measured when considering Huguier's canal morphology, DML and AML anatomy and the presence of pathologies in the stomatognathic and acoustic systems. The present descriptive study's restrictions include the absence of clinical corroborating information using adequate equipment for measuring morphological findings which could link this basic scientific research with future evidence-based studies.

\section{CONCLUSION} found that:

Bearing this study's limitations in mind, this article

There was an anatomical and functional relationship between human TMJ and the middle ear; interdisciplinary odontology and otolaryngology management is necessary for diagnosing difficult secondary otic symptoms; and future research is necessary for confirming these findings by using well-designed clinical studies.

\section{AKNOWLEDGMENTS}

We would like to thank Dr. Carlos Conde Cotes for his comments and editing later versions of this paper. We thank to the Instituto de Medicina Legal for his valuable help in donating sample material. 
RAMÍREZ, L. M.; BALLESTEROS, A. L. E. \& SANDOVAL, O. G. P. Estudio anatómico directo de la morfología y funcionalidad de los ligamentos disco-maleolar y maleolar anterior. Int. J. Morphol., 27(2):367-379, 2009.

RESUMEN: Los ligamentos disco-maleolar y maleolar anterior son comunes en el oído medio, la articulación temporomandibular y la mandíbula, todas ellos comparten un origen embriológico común. Los aspectos morfométricos y funcionales de estos ligamentos fueron estudiados en 23 huesos temporales. Diseño experimental: el techo del epitímpano y el techo de la articulación temporomandibular fue elevada mediante micro-disección de la fosa craneal media, exponiendo ambos ligamentos disco-maleolar y maleolar anterior y su asociación con el maleus, el disco de la articulación temporomandibular y língula mandibular. Principales observaciones: Ambos ligamentos comienzan en el maleus y toman una ruta anterior y divergente hacia la articulación temporomandibular y língula, pasando a través del canal de Huguier. Las longitudes medias del ligamento disco-maleolar y maleolar anterior fueron 6,88 mm (DS 0,81) y 4,2mm (DS 1,17), respectivamente, no fueron reveladas diferencias estadísticamente significativas entre las partes. La tracción del disco de la articulación temporomandibular fue aplicada para verificar la movilidad del maleus; el movimiento del maleus fue observado cuando se aplicó tracción del ligamento disco-maleolar en el 30,5\% de las muestras. Se observó correlación entre el movimiento del maleus y la longitud disco-maleolar $(\mathrm{R} 2=-0,499, \mathrm{p}<0,05)$. Ambos ligamentos comunes al sistema estomatognático y el oído medio estaban presentes en todos los especímenes. Conclusiones: Existe una relación anatómica y funcional entre la ATM humana y el oído medio.

PALABRAS CLAVE: Cadena oscicular; Articulación témporomandibular; Síntomas óticos; Ligamento disco-maleolar; Ligamento maleolar anterior.

\section{REFERENCES}

Abe, S.; Ouchi, Y.; Ide, Y. \& Yonezu, H. Perspectives on the role of the lateral pterygoid muscle and the sphenomandibular ligament in temporomandibular joint function. Cranio, 15:203-7, 1997.

Alkofide, E. A.; Clark, E.; el-Bermani, W.; Kronman, J. H. \& Mehta, N. The incidence and nature of fibrous continuity between the sphenomandibular ligament and the anterior malleolar ligament of the middle ear. J. Orofac. Pain, 11:714, 1997.

Allin, E. F. Evolution of the mammalian middle ear. $J$. Morphol, 147:403-37, 1975.

Ash, C. M. \& Pinto, O. F. The TMJ and the middle ear: Structural and functional correlates for otic symptoms associated with temporomandibular joint dysfunction. Int. J. Prosthodont., 4:51-7, 1991.

Baldursson, G. \& Blackmer, E. R. Temporomandibular joint symptoms in patients with midfrequency sensorineural hearing loss. Ear Hear, 8:63-7, 1987.

Békésy, G. V. Experiments in Hearing. New York, McGrawHill, 1960.

Bernstein, J. M.; Mohl, N. D. \& Spiller, H. Temporomandibular joint dysfunction masquerading as disease of ear, nose, and throat. Trans. Am. Acad. Ophthalmol. Otolaryngol., 73:1208-17, 1969.
Bossy, J. \& Gaillard, L. The Vestigial Ligaments Of Meckel's Cartilage. Acta Anat. (Basel), 52:282-90, 1963.

Burch, J. G. Activity of the accessory ligaments of the temporomandibular joint. J. Prosthet. Dent., 24:621-8, 1970.

Burch, J. G. The cranial attachment of the sphenomandibular (tympanomandibular) ligament. Anat Rec., 156:433-7, 1966.

Chan, S. W. \& Reade, P. C. Tinnitus and temporomandibular paindysfunction disorder. Clin. Otolaryngol. Allied Sci., 19:370-80, 1994.

Cheng, T. \& Gan, R. Z. Mechanical properties of anterior malleolar ligament from experimental measurement and material modeling analysis. Biomech. Model Mechanobiol., 7:387-94, 2008.

Cheynet, F.; Guyot, L.; Richard, O.; Layoun, W. \& Gola, R. Discomallear and malleomandibular ligaments: anatomical study and clinical applications. Surg. Radiol. Anat., 25:152-7, 2003.

Coleman, R. D. Temporoamndibular joint. Relations of the retrodiscal zone to Meckel's cartilage and lateral pterygoid muscle. J. Dent. Res., 49:626-30, 1970.

Costen, J. B. A syndrome of ear and sinus symptoms dependent upon disturbed function of the temporomandibular joint. Ann. Otol., 43:1-15, 1934. 
Dai, C.; Cheng, T.; Wood, M. W. \& Gan, R. Z. Fixation and detachment of superior and anterior malleolar ligaments in human middle ear: experiment and modeling. Hear Res., 230:24-33, 2007.

Dalhoff, E.; Turcanu, D.; Zenner, H. P. \& Gummer, A. W. Distortion product otoacoustic emissions measured as vibration on the eardrum of human subjects. PNAS, 104:1546-51, 2007.

Eckerdal, O. The petrotympanic fissure: a link connecting the tympanic cavity and the temporomandibular joint. Cranio, 9:15-22, 1991

Garg, A. \& Townsend, G. Anatomical variation of the sphenomandibular ligament. Aust. Endod. J., 27:22-4, 2001.

Gelb, H. \& Tarte, J. A two-year dental clinical evaluation of 200 cases of chronic headache: the craniocervicalmandibular syndrome. JADA, 91:1230-6, 1975.

Gola, R.; Chossegros, C. \& Cheynet, F. Oto-mandibular ligaments: disco-mallear and malleo-mandibular ligaments. Rev. Stomatol. Chir. Maxillofac., 98:66-71, 1997.

Hoshino, T. Surgical anatomy of the anterior epitympanic space. Arch. Otolaryngol. Head Neck Surg., 114:1143-5, 1988.

Huber, A.; Koike, T.; Wada, H.; Nandapalan, V. \& Fisch, U. Fixation of the anterior mallear ligament: diagnosis and consequences for hearing results in stapes surgery. Ann. Otol. Rhinol. Laryngol., 112:348-55, 2003.

Ioannides, C. A. The disco-malleolar ligament: A possible cause of subjective hearing loss in patients with TMJ. $J$. Maxillofac. Surg., 11:227-31, 1983.

Johansson, A. S.; Isberg, A. \& Isacsson, G. A radiographic and histologic study of the topographic relations in the temporomandibular joint region. J. Oral Maxilofac. Surg., 48:953-61, 1990.

Jones, J. L. \& Horn, K. L. The effect of temporomandibular joint arthroscopy on ear function. J. Oral Maxillofac. Surg., 47:1022-5, 1989.

Kim, H. J.; Jung, H. S.; Kwak, H. H.; Shim, K. S.; Hu, K. S.; Park, H. D.; Park, H. W. \& Chung, I. H. The discomallear ligament and the anterior ligament of malleus: an anatomic study in human adults and fetuses. Surg. Radiol. Anat., 26:39-45, 2004.
Koike, T.; Wada, H. \& Kobayashi, T. Modeling of the human middle ear using the finite-element method. J. Acoust. Soc. Am., 111:1306-17, 2002.

Komori, E.; Sugisaki, M. \& Tanabe, H. Discomalleolar ligament in the adult human. Cranio, 4:300-5, 1986.

Kuttila, S. \& Kuttila, M. Otic symtoms and signs of temporomandibular disorder in association with treatment need and visits to physician. Laryngoscope, 109:1669-73, 1999.

Kuttila, S. \& Kuttila, M. Secondary otalgy in adult population. AAO-HNS, 127:401-5, 2001.

Kuttila, S.; Kuttila, M.; Le Bell, B. Y.; Alanen, P. \& Suonpaa, J. Recurrent tinnitus and associated ear symptoms in adults. Int. J. Audiol., 44:164-70, 2005.

Libin, B. M. The cranial mechanism: Its relationship to craniomandibular function. J. Prosthet. Dent., 58:6328, 1987.

Loughner, B. A. \& Larkin, L. H. Discomalleolar and anterior malleolar ligaments: Possible causes of middle ear damage during temporomandibular joint surgery. Oral Surg. Oral Med. Oral Pathol., 68:14$22,1989$.

Luder, H. U. Articular degeneration and remodeling in human temporomandibular joints with normal and abnormal disc position. J. Orofacial Pain, 7:391-402, 1993.

Marasa, F. K. \& Ham, B. D. Case reports involving the treatment of children with chronic otitis media with effusion via craniomandibular methods. Cranio, 6:25670, 1988.

Mérida Velasco, J. R.; Rodríguez Vázquez, J. F. \& Jiménez Collado, J. Anterior tympanic artery: course, ramification and relationship with the temporomandibular joint. Acta Anat. (Basel), 158:222-6, 1997.

Misurya, V. K. Functional anatomy of tensor palati and levator palati muscles. Arch Otolaryngol., 102:265-70, 1976.

Morgan, D. H.; Goode, R. L.; Christiansen, R. L. \& Tiner, L. W. The TMJ-ear connection. Cranio, 13:42-3, 1995.

Myers, L. J. Possible inflammatory pathways relating temporomandibular joint dysfunction to otic symptoms. The J. Craniomand. Prac., 6:65-70, 1988. 
RAMíREZ, L. M.; BALLESTEROS, A. L. E. \& SANDOVAL, O. G. P. A direct anatomical study of the morphology and functionality of disco-malleolar and anterior malleolar ligaments. Int. J. Morphol., 27(2):367-379, 2009.

Myrhaug, $\mathrm{H}$. The incidence of ear symptoms in cases of malocclusion and temporo-mandibular joint disturbances. Br. J. Oral Surg., 2:28-32, 1964.

Nakajima, H. H.; Ravicz, M. E.; Rosowski, J. J.; Peake, W. T. \& Merchant, S. N. Experimental and clinical studies of malleus fixation. Laryngoscope, 115:147-54, 2005.

Ogutcen-Toller, M. The morphogenesis of the human discomalleolar and sphenomandibular ligaments. J. Craniomaxillofac. Surg., 23:42-6, 1995.

Ogutcen-Toller, M. \& Keskin, M. Computerized 3-dimensional study of the embryologic development of the human masticatory muscles and temporomandibular joint. J. Oral Maxillofac. Surg., 58:1381-6, 2000.

Ouchi, Y.; Abe, S.; Sun-Ki, R.; Agematsu, H.; Watanabe, H. \& Ide, Y. Attachment of the sphenomandibular ligament to bone during intrauterine embryo development for the control of mandibular movement. Bull. Tokyo Dent. Coll., 39:91-4, 1998.

Parker, W. S. \& Chole, R. A. Tinnitus, vertigo and temporomandibular disorders. Am. J. Orthod. Dentof. Orthop., 107:153-8, 1995.

Perry, H. T. \& Xu, Y. The embryology of the temporomandibular joint. J. Craniomandib. Pract., 3:125-32, 1985 .

Pinto, O. F. A new structure related to the temporomandibular joint and middle ear. J. Prosthet. Dent., 12:95-103, 1962.

Proctor, B. Embryology and anatomy of the eustachian tube. Arch. Otolaryngol., 86:503-14, 1967.

Ramirez, L. M.; Ballesteros, L. E. \& Sandoval, G. P. Topical review: temporomandibular disorders in an integral otic symptom model. Int. J. Audiol., 47:215-27, 2008.

Rees, L. A. The structure and function of the mandibular joint. Br. Dent. J., 96:125, 1954.

Regev, E.; Koplewitz, B. Z.; Nitzan, D. W. \& Bar-Ziv, J. Ankylosis of the temporomandibular joint as a sequela of septic arthritis and neonatal sepsis. Pediatr. Infect. Dis. J., 22:99-101, 2003.

Ren, Y. F. \& Isberg, A. Tinnitus in patients with temporomandibular joint internal derangement. Cranio, 13:75-80, 1995.
Rodriguez Vazquez, J. F.; Mérida Velasco, J. R. \& Jiménez Collado, J. A study of the os goniale in man. Acta Anat. (Basel), 142:188-92, 1991.

Rodriguez Vazquez, J. F.; Mérida Velasco, J. R. \& Jiménez Collado, J. Anatomical considerations on the discomalleolar ligament. J. Anat., 192:617-21, 1998.

Rodriguez Vazquez, J. F.; Mérida Velasco, J. R. \& Jiménez Collado, J. Development of the human sphenomandibular ligament. Anat. Rec., 233:453-60, 1992.

Rodriguez Vazquez, J. F.; Mérida Velasco, J. R. \& Jiménez Collado, J. Relationships between the temporomandibular joint and the middle ear in human fetuses. J. Dent. Res., 72:62-6, 1993.

Sadler, T. W. Langman Medical Embriology. México, Médica Panamericana, 1998.

Sato, I.; Arai, H.; Asaumi, R.; Imura, K.; Kawai, T, \& Yosue, T. Classifications of tunnel-like structure of human petrotympanic fissure by cone beam CT. Surg. Radiol. Anat., 30:323-6, 2008.

Schaefer, J. R. Pressure-pain threshol SD and MRI effusions in TMJ artharlgia. J. Dent. Res., 80:1935-9, 2001.

Scolozzi, P.; Becker, M. \& Richter. M. Temporomandibular joint osteoarthritis: a cause of a serous otitis media? A case report. J. Oral Maxillofac. Surg., 62:97-100, 2004.

Shapiro, H. H. \& Truex, R. C. The temporomandibular joint and the auditory function. J. Am. Dent. Assoc., 30:114768, 1943.

Steigerwald, D. P.; Verne, S. V. \& Young, D. A retrospective evaluation of the impact of temporomandibular joint arthroscopy on the symptoms of headache, neck pain, shoulder pain, dizziness, and tinnitus. Cranio, 14:46-54, 1996.

Strickland, E. M.; Hanson, J. R. \& Anson, B. J. Branchial sources of auditory ossicles in man. I. Literature. Arch. Otolaryngol., 76:100-22, 1962.

Sun, Q.; Gan, R. Z.; Chang, K. H. \& Dormer, K. J. Computerintegrated finite element modeling of human middle ear. Biomech. Model Mechanobiol., 1:109-22, 2002.

Takes, R. P.; Langeveld, A. P. \& Baatenburg de Jong, R. J. Abscess formation in the temporomandibular joint as a 
RAMíREZ, L. M.; BALLESTEROS, A. L. E. \& SANDOVAL, O. G. P. A direct anatomical study of the morphology and functionality of disco-malleolar and anterior malleolar ligaments. Int. J. Morphol., 27(2):367-379, 2009 .

complication of otitis media. J. Laryngol. Otol., 114:373$5,2000$.

Thilander, B. \& Carlsson, G. E. Postnatal development of the human temporomandibular joint. Acta Odontol. Scand., 34:117-26, 1976.

Toledo Filho, J. L.; Zorzetto, N. L. \& Navarro, J. A. Structures and relationships of the anterior malleus ligament. Anat. Anz., 158:13-22, 1985.

Tonndorf, J. \& Khanna, S. M. Tympanic-membrane vibrations in human cadaver ears studied by time-averaged holography. J. Acoust. Soc. Am., 52:1221-33, 1972.

Tóth, M.; Moser, G.; Patonay, L. \& Oláh, I. Development of the anterior chordal canal. Ann. Anat., 188:7-11, 2006.

Tsuyama, M.; Kondoh, T.; Seto, K. \& Fukuda, J. Complications of temporomandibular joint arthroscopy: a retrospective analysis of 301 lysis and lavage procedures performed using the triangulation technique. J. Oral Maxillofac. Surg., 58:500-5, 2000.

Wada, H.; Ando, M.; Takeuchi, M.; Sugawara, H.; Koike, T.; Kobayashi, T.; Hozawa, K.; Gemma, T. \& Nara, M. Vibration measurement of the tympanic membrane of guinea pig temporal bones using time-averaged speckle pattern interferometry. J. Acoust. Soc. Am., 111:2189-99, 2002.

Wada, H.; Metoki, T. \& Kobayashi, T. Analysis of dynamic behavior of human middle ear using a finite-element method. J. Acoust. Soc. Am., 92:3157-68, 1992.

Williamson, E. H. Interrelationship of internal derangements of the temporomandibular joint, headache, vertigo, and tinnitus: a survey of 25 patients. Cranio, 8:301-6, 1990.

Wong, G. B. Morphology of the developing articular disc of the human temporomandibular joint. J. Oral Maxillofac. Surg., 43:565-9, 1985.

Wright, E. F. \& Bifano, S. L. Tinnitus improvement through TMD therapy. J. Am. Dent. Assoc., 128:1424-32, 1997.

Yoshikuni, O. H. Development and histology of fibrous architecture of the fetal temporomandibular joint. Okajimas Folia Anat. Jpn., 70:1-6, 1993.

Youdelis, R. A. The morphogenesis of the human temporomandibular joint and associated structures. $J$. Dent. Res., 45:182-91, 1966.
Zhao, F.; Wada, H.; Koike, T.; Ohyama, K.; Kawase, T. \& Stephens, D. Middle ear dynamic characteristics in patients with otosclerosis. Ear Hear, 23:150-8, 2002.

\section{Correspondence to: \\ Dr. Luis Miguel Ramírez \\ Calle $45 \mathrm{~N}^{\circ} 33-17$ \\ Edificio La Nacional, Apto 702 B \\ Bucaramanga \\ COLOMBIA}

Fax: (097) 6479668

Email: Imra3@yahoo.com

Received: 09-03-2009

Accepted: 17-03-2009 
